ORNL/TM-1999/312

Chemical Technology Division

\title{
MEASUREMENT OF ACHIEVABLE PLUTONIUM DECONTAMINATION FROM GALLIUM BY MEANS OF PUREX SOLVENT EXTRACTION
}

\author{
E. D. Collins \\ D. O. Campbell \\ L. K. Felker
}

Date Published-January 2000

Prepared for the

Fissile Materials Disposition Program

\author{
Prepared by the \\ OAK RIDGE NATIONAL LABORATORY \\ Oak Ridge, Tennessee 37831-6285 \\ managed by \\ LOCKHEED MARTIN ENERGY RESEARCH CORP. \\ for the \\ U.S. Department of Energy \\ under contract DE-AC05-96OR22464
}




\section{CONTENTS}

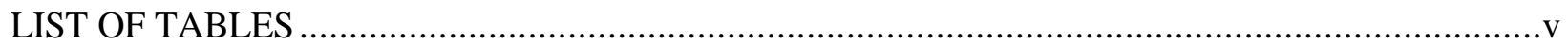

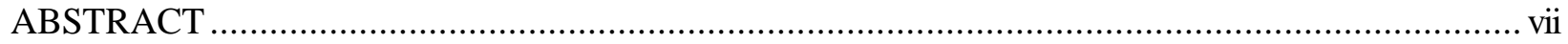

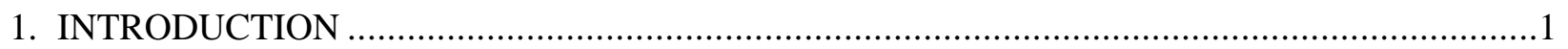

2. ESTIMATION OF GALLIUM REMOVAL REQUIREMENT …........................................

3. FACTORS AFFECTING IMPURITY REMOVAL (DECONTAMINATION) ...........................

3.1 GENERAL CONSIDERATIONS FOR RADIOCHEMICAL PROCESSING.....................4

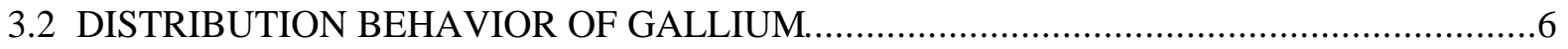

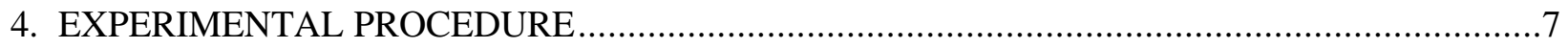

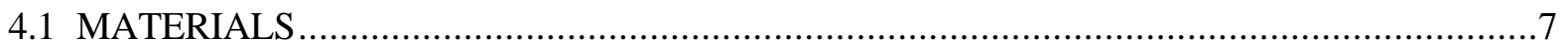

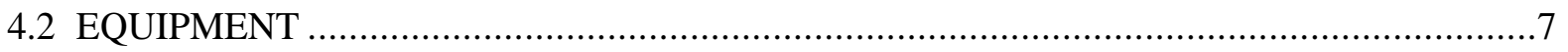

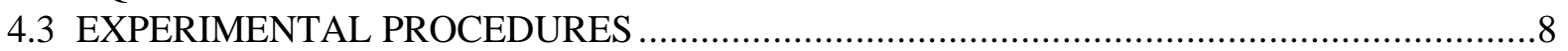

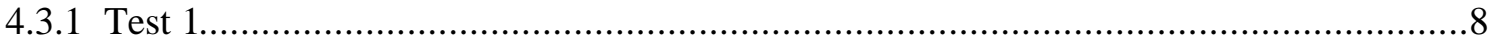

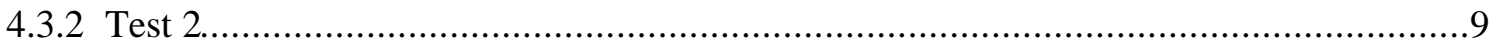

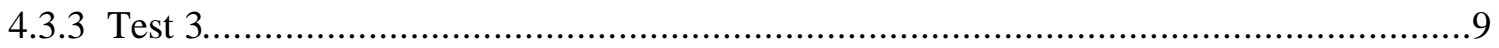

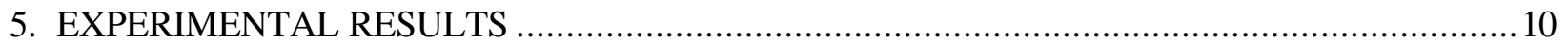

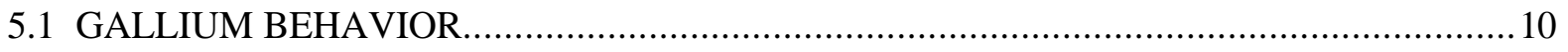

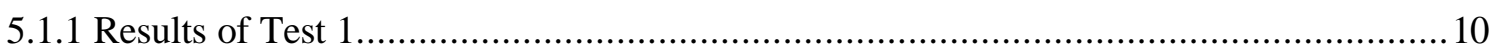

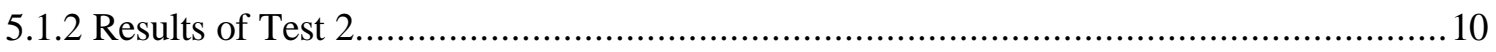

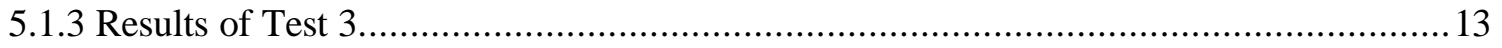

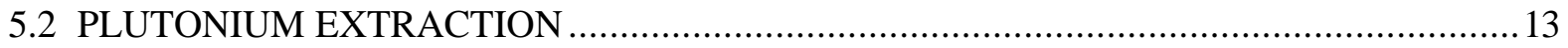

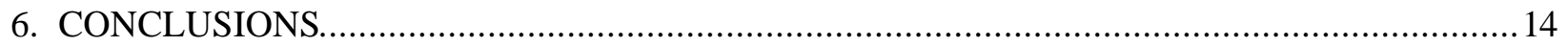

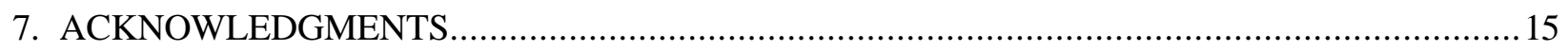

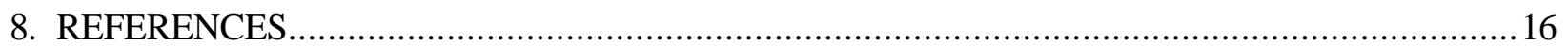




\section{LIST OF TABLES}

$\underline{\text { Table }}$

1 DFs observed in hot cell tests with third-cycle 20\% Pu MOX Fast-Flux Test Facility fuel...................5

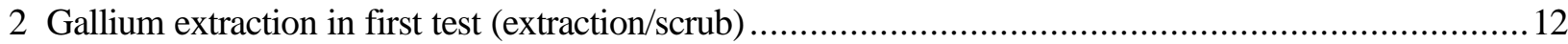

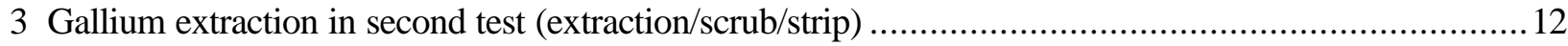

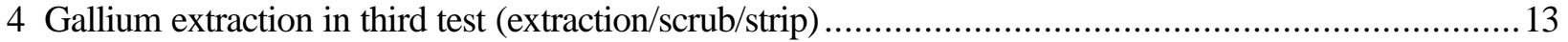

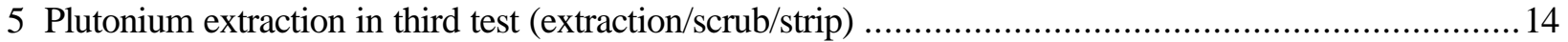




\begin{abstract}
The objective of the work described herein was to measure, experimentally, the achievable decontamination of plutonium from gallium by means of the PUREX solvent extraction process. Gallium is present in surplus weapons-grade plutonium (WG-Pu) at a concentration of approximately $1 \mathrm{wt} \%$. Plans are to dispose of surplus WG-Pu by converting it to $\mathrm{UO}_{2}-\mathrm{PuO}_{2}$ mixed oxide (MOX) fuel and irradiating it in commercial power reactors. However, the presence of high concentrations of gallium in plutonium is a potential corrosion problem during the process of MOX fuel irradiation. The batch experiments performed in this study were designed to measure the capability of the PUREX solvent extraction process to separate gallium from plutonium under idealized conditions. Radioactive tracing of the gallium with ${ }^{72} \mathrm{Ga}$ enabled the accurate measurement of low concentrations of extractable gallium. The experiments approximated the proposed flowsheet for WG-Pu purification, except that only one stage was used for each process: extraction, scrubbing, and stripping. With realistic multistage countercurrent systems, much more efficient separations are generally obtained. The gallium decontamination factor (DF) obtained after one extraction stage was about $3 \mathrm{H} 10^{6}$. After one scrub stage, all gallium measurements were less than the detection limit, which corresponded to DFs $>5 \mathrm{H} 10^{6}$. All these values exceed a $10^{6} \mathrm{DF}$ needed to meet a hypothetical 10-ppb gallium impurity limit in MOX fuel. The results of this study showed no inherent or fundamental problem with regard to removing gallium from plutonium.
\end{abstract}




\section{INTRODUCTION}

The objective of the work described herein was to measure, experimentally, the achievable decontamination of plutonium from gallium by means of the PUREX solvent extraction process. Gallium may be present in surplus weapons-grade plutonium (WG-Pu) at a concentration of approximately $1 \mathrm{wt} \%$. Plans are to dispose of surplus WG-Pu .by converting it to $\mathrm{UO}_{2}-\mathrm{PuO}_{2}$ mixed oxide (MOX) fuel and burning it in commercial power reactors. However, the presence of high concentrations of gallium in plutonium is a potential corrosion problem during the process of MOX fuel irradiation. ${ }^{1-4}$

Accordingly, the fuel qualification specifications for MOX fuel are expected to specify a maximum concentration of gallium, thus establishing a gallium removal, or decontamination factor (DF*), requirement for the plutonium. The maximum concentration of gallium in the plutonium feed to MOX fuel fabrication has not yet been determined; therefore, for the purposes of this study, a maximum concentration limit of 10 parts per billion (ppb) of plutonium was conservatively estimated, as described below, from available information with successful $\mathrm{UO}_{2}$ fuel experience. With the limit of $10 \mathrm{ppb}$ and a WG-Pu concentration of $1 \%\left(10^{7} \mathrm{ppb}\right)$, the DF required would be $10^{6}$.

The achievable extent of decontamination of the WG-Pu from gallium has not been well established experimentally. Expert opinions ${ }^{5}$ based on DFs measured for chemically similar elements indicate that the gallium can be removed by a factor of $10^{5}$ by means of the PUREX solvent extraction process and another factor of 10 by means of the oxalate precipitation/filtration process.

The batch experiments performed in this study were designed to measure the capability of the PUREX solvent extraction process to separate gallium from plutonium under idealized conditions. Radioactive tracing of the gallium with ${ }^{72} \mathrm{Ga}$ enabled the accurate measurement of low concentrations of extractable gallium.

\section{ESTIMATION OF GALLIUM REMOVAL REQUIREMENT}

There is an experience base for tolerable gallium contents that can be derived from the successful performance of conventional $\mathrm{UO}_{2}$ fuel. Since gallium is a fission product, the initial approach was to estimate the gallium content of spent fuel from the fission yield. Preliminary examination indicated that although the amount of fission product gallium is extremely small, there is a much larger production of gallium from neutron capture in the zinc impurity in the fuel and cladding. These sources generate a minimum gallium content that can be tolerated, based on satisfactory $\mathrm{UO}_{2}$ fuel performance experience.

Three sources of gallium exist in irradiated $\mathrm{UO}_{2}$ fuel: (1) gallium impurity in the fuel and cladding, which is not measured and is believed to be quite low; (2) fission product gallium; and (3) gallium formed by neutron capture in natural zinc impurity in the fuel. It is recommended that some effort be applied to establishing the gallium content of typical new and/or archived unirradiated $\mathrm{UO}_{2}$ fuel [source (1), above]; for the purposes of this study, this value is conservatively assumed to be zero and is not considered further. Estimates of the gallium content created by mechanisms (2) and (3) were generated from

\footnotetext{
* The DF is normalized to some measure of the system and will differ depending on that measure. In this report, it is normalized to the plutonium content. Specifically, it will be the ratio of gallium to plutonium concentrations, $[\mathrm{Ga}] /[\mathrm{Pu}]$, in the feed to that in the stream of interest.
} 
ORIGEN $^{6}$ calculations for normal $\mathrm{UO}_{2}$ fuel irradiation. These sources are considered in the following discussion.

In this study, only a rough estimate is needed, and it is estimated that fission product gallium in spent $\mathrm{UO}_{2}$

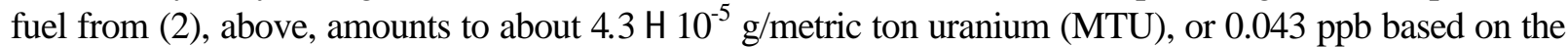
total uranium. In contrast, gallium from the zinc impurity [neutron capture in ${ }^{68} \mathrm{Zn}$ (18.8\% abundance) yields short-lived ${ }^{69} \mathrm{Zn}$, which decays to stable ${ }^{69} \mathrm{Ga}$ ] depends on the zinc impurity level but is clearly much greater. The corresponding reactions on ${ }^{70} \mathrm{Zn}$ to yield ${ }^{71} \mathrm{Ga}$ are negligible. If the zinc impurity is $40 \mathrm{ppm}$ in $\mathrm{UO}_{2}$ fuel (which is believed to be a typical value in early fuel), the gallium content at end of life (EOL) would be about $3.2 \mathrm{H} 10^{-2} \mathrm{~g} / \mathrm{MTU}$ ( $32 \mathrm{ppb}$ ), based on an ORIGEN calculation. The specification for zinc in $\mathrm{UO}_{2}$ fuel is $250 \mathrm{ppm}$, which would give a gallium content at $\mathrm{EOL}$ of $200 \mathrm{ppb}$. The current proposed fuel specification for MOX is $100 \mathrm{ppm}$ zinc, which would yield $80 \mathrm{ppb}$ gallium at EOL. Estimates indicate that current $\mathrm{UO}_{2}$ fuel may contain as little as 5 ppm zinc, which would yield 4 ppb gallium.

Thus, the gallium content in spent $\mathrm{UO}_{2}$ fuel that demonstrated satisfactory performance could be anywhere in the range from at least a few $(\sim 4) \mathrm{ppb}$ as a minimum, up to perhaps $200 \mathrm{ppb}$, with values well up into this range almost certainly having performed acceptably. As a conservative approach in this study, the target gallium content in MOX fuel will be $10 \mathrm{ppb}$ (average over exposure life). In fact, it is possible that the acceptable concentration may be in the range specified for most impurities in $\mathrm{UO}_{2}$, which is 10-100 ppm, or 3 to 4 orders of magnitude larger. It is believed conservative to assume that, if fuel can be produced with about $10 \mathrm{ppb}$ gallium, then gallium will not present a new fuel performance issue.

Conversion of the $\mathrm{UO}_{2}$ fuel performance estimate, based on the gallium content increasing from near-zero initially to a value in the range of multiple ppb at EOL, to a specification for gallium content of initial fuel necessarily involves some assumptions. For example, in order to explore the problem on a somewhat simplified basis, it will be assumed that the cladding life is linearly proportional to the inverse of the integral of the gallium content times the exposure time and that gallium grows in from neutron capture in zinc at a rate linearly proportional to the exposure time. This assumption implies that an average concentration of $10 \mathrm{ppb}$ gallium - present initially, produced from zinc during irradiation, or both —would be satisfactory throughout the life of the fuel. If less zinc is present, less gallium will be produced by activation and therefore more gallium can be present in the initial fuel.

The ORIGEN calculation yields the result that $1 \mathrm{ppm}$ zinc in initial $\mathrm{UO}_{2}$ fuel results in $0.8 \mathrm{ppb}$ gallium at EOL. Then,

and

$$
\mathrm{Ga}(\mathrm{EOL}, \mathrm{ppb})=\mathrm{Ga}(\text { initial, ppb) + } 0.8 \mathrm{Zn} \text { (initial, ppm), }
$$

$$
\text { Ga (average, ppb) = Ga (initial, ppb) + 0.4 Zn (initial, ppm). }
$$

As noted in Eqs. (1) and (2), it will be assumed that fuel performance will be satisfactory if this final quantity, gallium (average, ppb), is $\leq 10 \mathrm{ppb}$. In actuality, a much higher gallium content is likely to be satisfactory. This limit might be increased by a large factor if adequate characterization data (specifically, gallium and zinc contents and irradiation history) of fuel that performed satisfactorily can be identified. Otherwise, an increased specification would depend on an expensive test program.

The interaction between initial gallium in the plutonium and gallium resulting from neutron capture in zinc is difficult to determine, primarily because plutonium constitutes only about $5 \%$ of the final MOX fuel. Thus, it is the zinc (and gallium) specification in the uranium (95\% of the heavy metal) used to make the MOX 
that may dominate the gallium content. The zinc specification for $\mathrm{UO}_{2}$ fuel $(250 \mathrm{ppm})$ was based on some factor other than gallium ingrowth, so that value is largely irrelevant to this discussion. The higher range of zinc contents actually used in the $\mathrm{UO}_{2}$ fuel that performed satisfactorily has real significance. The zinc content is believed to range around 5-10 ppm in current fuels, but it may well have been appreciably higher in the past—likely in the vicinity of $40 \mathrm{ppm}$, and possibly close to the specification limit of $250 \mathrm{ppm}$ in some fuel.

The zinc contents of both the uranium and plutonium used to make the MOX are variables that can be specified. The purification process to remove gallium from plutonium will also reduce zinc to a very low level, compared with the previously noted values; therefore, it is assumed that zinc in the plutonium will be a negligible contributor of gallium. Similarly, it will be assumed that only an extremely small quantity of gallium exists in the uranium used to make the MOX and that it can be neglected. However, this should be verified by analysis. (Note that if it is significant, it was also likely present in previously irradiated fuel and therefore would not present a "new" source of gallium.) Then, assuming the MOX is 5\% plutonium and 95\% uranium, Eq. (2) becomes

$$
\mathrm{Ga}(\text { average, ppb) }=0.05 \mathrm{HGa}(\mathrm{Pu}, \mathrm{ppb})+0.95 \mathrm{H} 0.4 \mathrm{HZn}(\mathrm{U}, \mathrm{ppm}) \leq 10 \mathrm{ppb} \text {. }
$$

If the uranium contains no zinc, the gallium content of the plutonium could be as high as $200 \mathrm{ppb}$. At the other extreme, if the zinc content of the uranium exceeds $26 \mathrm{ppm}$, the average gallium content would exceed the 10-ppb limit even if no gallium were present in either the uranium or the plutonium. Presumably, $\mathrm{UO}_{2}$ fuel containing higher levels of zinc than this has performed satisfactorily, indicating that the reasoning used here is conservative. At the same time, however, it is clear that zinc impurity in the uranium is the dominant source; this factor should be taken into account in setting specifications for the materials used for MOX production.

An alternative (and simpler) approach to the problem of balancing the gallium and zinc specifications is to require the plutonium to contribute no more gallium (per gram of plutonium) than the uranium contributes (per gram of uranium) on a pro-rata basis. Then, the plutonium specification would be

$$
\mathrm{Ga}(\text { average } \mathrm{Pu}, \mathrm{ppb})=\mathrm{Ga}(\mathrm{Pu}, \mathrm{ppb})+0.4 \mathrm{HZn}(\mathrm{Pu}, \mathrm{ppm}) \leq 10 \mathrm{ppb} \text {. }
$$

Since the zinc impurity level in plutonium feed to the purification process (likely $<100 \mathrm{ppm}$ ) will be much smaller than the gallium concentration $(1 \%=10,000 \mathrm{ppm})$, and the DFs for both gallium and zinc are expected to be large and comparable, the concentration of zinc in the purified plutonium will likely be much smaller than that of gallium, certainly $<<1 \mathrm{ppm}$. Thus, the gallium contribution from zinc will be very small compared with the 10-ppb limit for gallium. The issue then is ensuring a gallium content in the purified plutonium of $<10 \mathrm{ppb}$. This approach is conservative, because it does not allow for the possibility of reducing gallium production from zinc impurity in the uranium, thereby permitting more gallium to be present in the initial plutonium.

For the scoping purpose of this report, an objective is established of $\leq 10 \mathrm{ppb}$ gallium in the plutonium product from purification processing. At the same time, it is recognized that a large factor of conservatism probably exists in this value, possibly by several orders of magnitude. This specification can be translated into a required DF of $10^{6}$ for gallium in the plutonium to be processed $\left(10^{7} \mathrm{ppb}\right.$ gallium in feed plutonium divided by $10 \mathrm{ppb}$ gallium in product plutonium). 


\section{FACTORS AFFECTING IMPURITY REMOVAL (DECONTAMINATION)}

\subsection{GENERAL CONSIDERATIONS FOR RADIOCHEMICAL PROCESSING}

In radiochemical separations processing, two classes of factors can limit the degree of separation obtained: chemical and physical. As used here, "chemical" factors relate to inherent characteristics that prevent efficient separations, such as similar chemical properties (e.g., as with neptunium and plutonium), multiple species with a variety of chemical properties (e.g., ruthenium and zirconium), and synergistic interactions (e.g., between technetium and zirconium). "Physical" factors relate to variables such as incomplete or poor phase separation, emulsions, and phase entrainment or carry-over (which are affected by the way the system is operated). Such factors also include interfacial crud (often related to feed clarification and solvent damage), adsorption-desorption on solid surfaces (such as the equipment walls, interfacial crud, and suspended solids), flow mixing (such as dead-legs in valves and branch lines), etc. Some of these are basically chemical in nature (such as adsorption), but, to varying degrees, the physical factors are the result of system design and the mode of operation rather than of inherent properties of nature.

The experiments performed in this study were designed to test for any unanticipated problem that would interfere with attainment of very large DFs with respect to the chemistry of the system. Thus, they are idealized and not representative of actual plant operations. If these prove to be satisfactory, it will still be necessary to design the system to minimize the various mechanisms that can lead to product contamination and to operate it properly. These variables can be controlled to a large degree, whereas the chemical factors are inherent. Also, the presence of other impuritues, such as chloride, may degrade the gallium DF achieved.

The separations process planned for the aqueous processing head-end of the MOX Fuel Fabrication Facility will use a multistage countercurrent solvent extraction system involving (1) several stages for extraction of plutonium (and uranium, if present) from an aqueous feed solution into an organic tributyl phosphate (TBP) solution, (2) several stages of "scrubbing" of impurities (including $\mathrm{Ga}, \mathrm{Zn}, \mathrm{Cr}, \mathrm{Fe}, \mathrm{Cl}, \mathrm{F}$, and essentially all impurities) from the TBP solution, (3) several stages of "stripping" of the plutonium from the organic solvent into an aqueous solution, and (4) (if uranium is present) several stages of stripping the uranium from the organic solvent into an aqueous solution.

The result is four output streams: an aqueous raffinate (waste) containing the impurities; an aqueous plutonium product; an aqueous uranium product (if uranium is present); and the stripped organic TBP stream, which is recycled. The aqueous waste would be evaporated, conditioned, and solidified for disposal. The plutonium product would then become the plutonium feed to the oxalate precipitation process. The uranium product would be evaporated and the uranium stored or disposed of as waste. The stripped TBP organic solvent stream would be recycled after being treated to remove solvent degradation products, and the small quantity of aqueous waste generated by this treatment would be evaporated and solidified for disposal.

In a multistage countercurrent system, the individual separation obtained in each stage is multiplied through all stages, so that even a reasonably modest separation factor (such as 10 per stage) would lead to a very large separation for a complete contactor system containing, for example, five or ten stages $\left(10^{5}\right.$ and $10^{10}$, respectively). With a large single-stage separation factor, such as $10^{4}$, five stages would theoretically provide separation by a factor of $10^{20}$, but this does not occur. In actual practice, the separation factor per stage decreases greatly after a fairly large overall separation factor has been achieved. This typically 
occurs after the DF for impurities that have straightforward properties reaches a value in the general range of, for example, $10^{5}-10^{6}$. The DF may be lower in a poorly designed or inefficiently operated system and somewhat higher in a well-designed and well-operated system. The attainment of much higher DFs (e.g., $10^{10}$ ) generally requires the use of two or three such systems in series, each completely separated from the other, except that the product of the first becomes the feed for the second, etc.

The reasons that the very high DFs theoretically anticipated are not observed relate to both physical and chemical factors that are not completely understood. ${ }^{7}$ Each element may exist in several different chemical forms, including that adsorbed on surfaces. Each form will distribute differently between the two phases. The most extractable species will be extracted and removed more rapidly, leaving (after a few stages) only the less-extractable species, which will then be removed more slowly (if at all). Thus, the stage-to-stage effectiveness decreases as the extraction proceeds and can change by extremely large factors. This sort of behavior is a particular problem with fission product elements like $\mathrm{Ru}, \mathrm{Zr}$, and $\mathrm{Tc}$ in fuel reprocessing. In contrast, "well-behaved" elements like cesium, strontium, and rare earths exhibit such behavior to a much smaller extent. One objective of these experiments was to show that this complication did not arise with gallium within the range of DFs that is needed.

Even if the chemistry does not lead to the problems previously described, the physical factors will still limit the overall degree of separation achieved in a single piece of equipment. The general range of performance that might be expected can be estimated by considering the large experience base from reactor fuel reprocessing. In large-scale plant operations, it is common for one cycle of solvent extraction to yield a DF of about $10^{4}$ on a time-average basis with generally good operation. This might be somewhat better during "good" periods, and considerably worse during "bad" periods. DFs lower than $10^{3}$ are generally associated with poor operating characteristics due to a specific cause. DFs higher than $10^{5}$ are sometimes observed with very good plant design and operations. Very high DFs $\left(>10^{8}\right)$ are observed only with multiple purification cycles in series.

The DF is usually limited by one or two specific isotopes, zirconium and/or ruthenium. Other fission products that have simpler chemistries and are generally inextractable (such as $\mathrm{Ce}, \mathrm{Cs}, \mathrm{Eu}$, and $\mathrm{Sr}$ ) generally show higher DFs, by perhaps a factor of 10 (and sometimes much greater). Gallium is expected to be in this latter category of well-behaved elements. Detailed studies in hot cell tests conducted under more carefully controlled conditions, using 16-stage mixer-settlers, yield higher DFs, as shown in Table $1 .^{8}$ This indicates that elements which do not form extractable species (like cesium and the rare earths) give

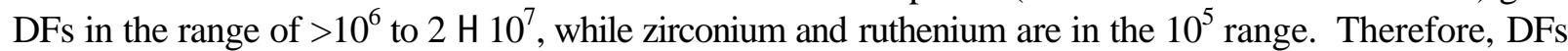
in the $10^{6}$ range are possible with a single processing cycle. In these tests, conditions were chosen to maximize DFs for zirconium and ruthenium, so the values reported for these elements are larger than those often observed. However, all of these DFs are still very much lower than one would calculate from single-stage data, and they demonstrate that physical factors eventually limit the achievable DF.

Table 1. DFs observed in hot cell tests with third-cycle $20 \% \mathrm{Pu}$ MOX Fast-Flux Test Facility fuel

\begin{tabular}{llc}
\hline & \multicolumn{2}{c}{ DF for isotope in plutonium product } \\
\cline { 2 - 3 } Isotope & $30 \% \mathrm{TBP}$ & $10 \% \mathrm{TBP}$ \\
\hline${ }^{95} \mathrm{Zr}$ & $2 \mathrm{H} 10^{5}$ & $2 \mathrm{H} 10^{5}$ \\
${ }^{106} \mathrm{Ru}$ & $>4 \mathrm{H} 10^{5}$ & $>8 \mathrm{H} 10^{5}$ \\
${ }^{137} \mathrm{Cs}$ & $2 \mathrm{H} 10^{7}$ & $8 \mathrm{H} 10^{6}$
\end{tabular}


Table 1. DFs observed in hot cell tests with third-cycle $20 \%$ Pu MOX

Fast-Flux Test Facility fuel

\begin{tabular}{llc}
\hline & \multicolumn{2}{c}{ DF for isotope in plutonium product } \\
\cline { 2 - 3 } Isotope & $30 \% \mathrm{TBP}$ & $10 \% \mathrm{TBP}$ \\
\hline${ }^{144} \mathrm{Ce}$ & $>2 \mathrm{H} 10^{7}$ & $1 \mathrm{H} 10^{7}$ \\
${ }^{154} \mathrm{Eu}$ & $>1 \mathrm{H} 10^{6}$ & $>2 \mathrm{H} 10^{6}$ \\
\hline
\end{tabular}

\subsection{DISTRIBUTION BEHAVIOR OF GALLIUM}

Very few data are available for the extractability of gallium in the PUREX system. In a review article, Orth, Wallace, and Karraker state that gallium has a low distribution coefficient but that chloride complexing makes gallium highly extractable in high-TBP and high-chloride concentrations. ${ }^{9}$ This latter condition is not applicable to our research; therefore, extractability is expected to be low. It is noted that there is a typographic error in their table. Gallium is incorrectly listed as "Ge" under group III-B elements; germanium is correctly listed under group IV-A.

Screening tests of nearly all the elements in the periodic table (at tracer level), using a range of concentrations of $\mathrm{HNO}_{3}$ versus $100 \%$ TBP, indicate distribution coefficients ( $\mathrm{K}_{\mathrm{d}}$ values) in the vicinity of $10^{-4}$ for gallium. ${ }^{10}$ Because of the law of mass action, $\mathrm{K}_{\mathrm{d}}$ values for gallium in the $30 \% \mathrm{TBP}$ system would be expected to be much smaller, by more than an order of magnitude. Although this supports the proposition that gallium is well behaved and essentially inextractable in the $\mathrm{HNO}_{3}-\mathrm{TBP}$ system, another publication by the same authors shows that gallium is extractable in the HCl-TBP system, with a $\mathrm{K}_{\mathrm{d}}$ of about $10^{3}$ in 2-10 $\mathrm{M} \mathrm{HCl}$, but decreasing to about 1 in low-acid conditions. ${ }^{11}$ Kraus and Nelson report similar behavior in low and moderate $\mathrm{HCl}$ concentrations but even larger $\mathrm{K}_{\mathrm{d}}$ values above $6 \mathrm{MHCl}$, in the $\geq 10^{4}$ range. $^{12}$

These references demonstrate that decontamination from gallium should present no unusual problem in PUREX separations with reasonably pure systems $\left(\mathrm{HNO}_{3}\right.$-TBP). However, gallium can be highly extractable into TBP in other chemical environments, such as $\mathrm{HCl}$. It is possible that impurities (such as chloride, fluoride, sulfate, and chromate) might cause extractable species of gallium to be formed. The question then becomes one of estimating whether or not the actual impurities in the plutonium provided for this program would cause difficulties. In the case of the plutonium alloy recovered from dismantled weapons, any impurities that might cause gallium to be extractable are expected to be present at such low concentrations that they would cause no problem.

Impure plutonium derived from sources in the weapons program other than the pure alloys may require purification with the same cleanup system prior to conversion to MOX. Normal PUREX processing is expected to perform satisfactorily, even with such impure feed material, because of the effectiveness of multistage countercurrent scrubbing. Some uncertainty, however, remains. Therefore, it is strongly recommended that the decontamination effectiveness of the process be evaluated in the context of the full range of various impurities that may be encountered in any given batch of feed. For example, some feed to the process could likely have relatively high chloride and/or fluoride concentrations, as well as other impurities; however, the maximum concentrations that can be tolerated are not known. Once the impurity contents of the various plutonium feeds to the process are defined, the literature should be examined for relevant data. In the absence of such data for complex mixed compositions, it is further recommended that additional testing be done to verify the performance of PUREX with impure feeds. 
In summary, limited available evidence strongly suggests that the extraction of gallium will present no unusual problem in the PUREX extraction system. The normal factors limiting the DF will be present, and these should depend largely on the equipment design and careful attention to operations. Under favorable conditions, DFs in the $10^{6}$ range, or possibly somewhat greater, should be obtained. This, in combination with the DF provided by other steps in the MOX flowsheet (such as oxalate precipitation), appears to provide adequate decontamination to meet the specifications discussed in the previous section. The possible exception to this conclusion could be presented by very impure feeds containing constituents that specifically interfere with gallium separation. Therefore, impure feed materials should be examined in regard to this concern.

\section{EXPERIMENTAL PROCEDURE}

\subsection{MATERIALS}

A gallium stock solution was prepared by dissolving $2.018 \mathrm{~g}$ of natural gallium metal in $10 \mathrm{~mL}$ of concentrated $\mathrm{HNO}_{3}$. The resulting solution was clear and light green in color. Deionized water was added to bring the volume to $100 \mathrm{~mL}$, and the resulting solution was sampled and analyzed for acid. This stock solution was $20 \mathrm{~g} / \mathrm{L}$ in gallium and $1.0 \mathrm{M}$ in $\mathrm{HNO}_{3}$.

The gallium sample for activation to provide the ${ }^{72} \mathrm{Ga}$ tracer for extraction experiments was prepared by pipetting measured aliquots of the stock solution into a 2-mm-ID by 4-mm-high quartz cup, slowly evaporating the solution to dryness, and wrapping the cup in aluminum foil. This sample was transferred to the Neutron Activation Group of the Chemical and Analytical Sciences Division (CASD) for irradiation in the pneumatic tube facility at the High Flux Isotope Reactor. The gallium was irradiated at $4 \mathrm{H} 10^{14}$

neutrons $/\left(\mathrm{cm}^{2} @\right.$ for specified times to produce the ${ }^{72} \mathrm{Ga}$ tracer isotope (13.95-h half-life) used for the test. Short-lived ${ }^{70} \mathrm{Ga}$ (21-min half-life), formed as a by-product, was allowed to decay before the experiments were started. The gallium tracer was readily dissolved from the quartz cup with dilute $\mathrm{HNO}_{3}$.

The plutonium stock solution was prepared by adjusting the volume and acid concentration of a solution currently in inventory at the Radiochemical Engineering Development Center at Oak Ridge National Laboratory. A $30-\mathrm{mL}$ sample of the inventory solution was volume reduced by evaporation to approximately $3 \mathrm{~mL}$ and then diluted to $12 \mathrm{~mL}$ to yield a plutonium stock solution containing $172 \mathrm{~g} / \mathrm{L}$ plutonium in $4.0 \mathrm{M} \mathrm{HNO}_{3}$.

TBP was obtained from the Stauffer Chemical Company. The $n$-paraffin hydrocarbon (NPH) solvent (Norpar®-12) was obtained from Exxon Chemical Company. A 30 vol \% TBP stock solution was prepared by diluting $30 \mathrm{~mL}(28.11 \mathrm{~g})$ of TBP to $100 \mathrm{~mL}$ with NPH. The $30 \%$ TBP solution was scrubbed twice with equal volumes of $0.25 \mathrm{M}$ sodium carbonate, followed by a water wash. The TBP used in each extraction test was equilibrated with dilute $\mathrm{HNO}_{3}$ just before its use in the extraction tests, as outlined in the extraction procedure. All other solutions were prepared from reagent-grade chemicals, and concentrations were checked as needed for the experiments.

\subsection{EQUIPMENT}

The extraction tests were sized to utilize 15-mL centrifuge cones for batch mixing of the aqueous and organic phases. The cones allowed for good separation of the phases, and the organic phase was centrifuged to further remove any entrained aqueous before the gamma-counting samples were taken. 
Because of the high alpha activity, all experimental work was done in a glove box, and the limited space available required that all equipment be compact. The phases were mixed using a Vortex-Genie Shaker equipped with a platform head to hold the centrifuge cones horizontally during mixing. The organic phases were centrifuged before final sampling using a Clay-Adams Compact II centrifuge (capable of $3200 \mathrm{rpm}$ ) that could accommodate the 15-mL centrifuge cones. Eppendorf adjustable model pipetters, used for sampling, were calibrated prior to use in the glove box experiments.

The Transuranium Analysis Group within CASD performed the gamma spectrometry measurements to determine the gallium concentrations of the various samples. The high-purity germanium (HPGe) detectors are $\mathrm{N}$-type coaxial with beryllium windows and aluminum end caps, manufactured by Princeton Gamma-Tech and Oxford Instruments. They are nominally 30\% efficient relative to a 3- x 3-in. NaI detector and have a resolution (full width at half-maximum) of $1.8 \mathrm{keV}$ at $1332 \mathrm{keV}$.

Plutonium concentrations were determined by the same group. Gross alpha counts were measured with a windowless gas-flow proportional counter, utilizing $2 \pi$ geometry, manufactured by the Nuclear Measurements Company. Alpha spectrometry was performed using silicon surface-barrier detectors having a $450-\mathrm{mm}^{2}$ active surface area and an alpha resolution of $25 \mathrm{keV}$. The surface-barrier detectors were manufactured by Tennelec/Oxford Instruments. Both gamma and alpha spectra were analyzed using a Nuclear Data/Canberra Genie VAX-based multichannel analyzer.

\subsection{EXPERIMENTAL PROCEDURES}

\subsubsection{Test 1}

The first extraction and scrubbing test was performed to check the equipment performance and efficiency, measurements methods, and radiation exposure considerations for the glove box operations. The ${ }^{72} \mathrm{Ga}$ tracer was generated by irradiating $0.5 \mathrm{mg}$ of gallium from the stock solution for $2 \mathrm{~min}$, as previously described. Measured volumes of the plutonium stock solution $(1.176 \mathrm{~mL})$, the gallium stock solution $(0.075$ $\mathrm{mL})$, and the dissolved gallium tracer $\left(2.5 \mathrm{~mL}\right.$ in $\left.4.0 \mathrm{MHNO}_{3}\right)$ were combined and diluted to $5.0 \mathrm{~mL}$ with $4 \mathrm{MHNO}_{3}$. This resulted in $5.0 \mathrm{~mL}$ of feed solution containing $200 \mathrm{mg}$ plutonium and $2 \mathrm{mg}$ gallium (including the tracer gallium) in $4 \mathrm{M} \mathrm{HNO}_{3}$. The $30 \%$ TBP extractant $(6 \mathrm{~mL})$ was equilibrated with an equal volume of $0.5 \mathrm{MHNO}_{3}$ prior to use.

After the feed solution has been sampled for analysis, the aqueous feed and the organic extract were combined in a $15-\mathrm{mL}$ centrifuge cone and agitated for $15 \mathrm{~min}$ on the shaker. The cone was removed from the shaker, and the phases separated readily. After a few minutes, the aqueous phase was withdrawn from the bottom of the cone with a Pasteur pipette and transferred to a separate sample bottle. Essentially all the gamma activity followed the aqueous phase. The organic phase remaining in the centrifuge cone was then centrifuged for 2-3 min to separate any entrained aqueous material. A 4-mL sample of the organic was subsequently removed and transferred to a sample bottle for counting the gallium gamma emission with the HPGe detectors. Finally, a dilution sample of each phase was prepared for alpha counting and alpha spectrometry.

After the extract sample had been counted for $1 \mathrm{~h}$, the organic phase was transferred to a new centrifuge cone. The residual organic left in the original cone that had been used for extraction was also carefully recovered and combined with the organic from the sample to provide the feed to the scrub step. An acid scrub solution of $2.5 \mathrm{~mL}$ of $4 \mathrm{MHNO}_{3}$ was added to the centrifuge cone and agitated on the shaker for 
15 min. The separation of phases, centrifuging, sampling, and counting were repeated for the organic extractant and aqueous scrub phases in the same manner as previously described for the extraction step.

\subsubsection{Test 2}

The results of test 1 showed that a very large gallium DF was obtained in the extraction step but that the actual value could not be determined because the gallium content of the organic extract was below the limit of detection. The experience also showed that a substantially higher gallium activation level was experimentally practical. Based on observations in the first test, the procedure for the second test was modified to achieve two purposes: (1) to extend the range of sensitivity by increasing the gallium activation level and (2) to more closely mimic flowsheet conditions proposed for the actual process. The changes are summarized as follows:

- The gallium tracer activity was increased by irradiating $0.8 \mathrm{mg}$ gallium for $14 \mathrm{~min}$.

- The $30 \%$ TBP extractant was preequilibrated with an equal volume of $0.19 M \mathrm{HNO}_{3}$. Equal volumes $(5.0 \mathrm{~mL})$ of both feed and extractant were used. The feed acidity was increased from 4.0 to $4.5 \mathrm{M}$, while the aqueous scrub acidity was decreased from 4.0 to $1.5 \mathrm{MHNO}_{3}$. The phase ratio (organic extract/aqueous scrub) was increased to $3(1.66 \mathrm{~mL}$ scrub). A third step was added to the process, namely stripping plutonium from the scrubbed organic. The strip solution was $5.0 \mathrm{~mL}$ of $0.4 \mathrm{M}$ hydroxylamine nitrate (HAN) in $0.1 M^{-} \mathrm{HNO}_{3}$. This solution was mixed with the organic phase for 2-3 min every $10 \mathrm{~min}$ for a total of $30 \mathrm{~min}$ prior to phase separation. The experimental and analytical procedures were generally the same as those indicated for test 1.

\subsubsection{Test 3}

The results of test 2 demonstrated a larger gallium DF than for test 1 , but the gallium content of the organic extract was still below the limit of detection. Thus, a higher activation level was desired. However, a new complication appeared during the scrub and strip stages of the experiment, namely discrepancies in the material balances, such that the separated phases contained much more gallium than the feed. This observation is characteristic of contamination of the samples with gallium activity. Such contamination can occur either internally (e.g., by entrainment of a very small amount of aqueous phase with the organic samples) or externally (e.g., by transfer of activity from the gloves to the sample bottles during handling in the glove box). Procedures were subsequently modified to minimize both these mechanisms for cross-contamination.

The procedures for test 3 were identical to those for test 2 except for changes (1) to increase the gallium specific activity (thereby increasing experimental sensitivity), (2) to reduce interference from contamination, and (3) to improve the effectiveness of the plutonium strip procedure. These changes can be summarized as follows:

1. The entire $2 \mathrm{mg}$ gallium used in the test was irradiated for $20 \mathrm{~min}$ to generate a higher gallium activity level in the feed.

2. The plutonium strip procedure was modified to include two successive strip stages (instead of only one), each with $5 \mathrm{~mL}$ of the same strip composition as for test 2.

3. Major changes were made in the sampling procedures to prevent cross-contamination, as follows: 
a. To avoid aqueous-phase carry-over, approximately $0.1 \mathrm{~mL}$ of organic was left in the bottom of the centrifuge cone when the organic was removed from the extraction cone and transferred as feed to the scrub step. Similarly, following the scrub step, about $0.1 \mathrm{~mL}$ of organic was left during the transfer of organic from the scrub cone to the strip step. These changes were designed to minimize entrainment of aqueous phase (high gallium concentration) with the organic feed (very low gallium concentration) to the next step of the flowsheet.

b. To minimize external contamination of sample bottles from handling in the glove box, each sample bottle was placed in an individual bag so that the glove box gloves did not contact the sample bottle during sampling and removal of the bottles. To further reduce cross-contamination, CASD personnel made a second transfer of the organic samples to another clean sample bottle that was used for gamma counting.

The results of the experiment indicate that these measures were successful, since the difficulties with high material balances were eliminated.

\section{EXPERIMENTAL RESULTS}

\subsection{GALLIUM BEHAVIOR}

\subsubsection{Results of Test 1}

The first experiment was carried out both to provide useful data and to establish a base point from which conditions could be optimized for subsequent tests. In particular, the level of activation of the gallium is a key variable since a higher value increases the experimental sensitivity for measuring the distribution coefficient but also increases the level of radiation exposure to the personnel carrying out the test. The results are summarized in Table 2.

The gallium concentrations in the organic extract and the scrubbed organic were reported as less than the limit of detection, which was in the range of $1-3 \mathrm{~Bq} / \mathrm{mL}$ (95\% confidence level). This precluded demonstrating $\mathrm{K}_{\mathrm{d}}$ values less than about $10^{-5}$, which correspond to a gallium DF of greater than about $\sim 10^{5}$ in this experiment. This result was obtained with only one cycle of extraction and scrub. Additional cycles would be expected to yield substantially larger DFs, but that would result in values below the detection limit, which could not be measured.

The limit of measurement of DF (and of $K_{d}$ ) is essentially determined by the initial (feed) activity and the counting equipment available. To demonstrate higher DFs, as well as to achieve an actual measurement rather than a limit, a larger gallium feed activity is necessary. Accordingly, the irradiation time for activation of the gallium was increased for the second experiment. In addition, a plutonium strip step was included, using $\mathrm{HAN}$ in dilute $\mathrm{HNO}_{3}$.

\subsubsection{Results of Test 2}

The results from the second experiment are summarized in Table 3. Again, the organic extract was below the limit of detection, corresponding to a DF of $>3 \mathrm{H} 10^{5}$. However, in the scrub and (especially) in the strip steps, the equilibrated phases contained considerably more gallium activity than should have been in the organic feed to those steps. This is generally an indication of contamination from the high-activity 
aqueous feed to the low-activity fractions. The question is whether the contamination is internal (carryover of some aqueous or insoluble material with the decontaminated organic extract) or external (transfer of activity to the outside of the sample bottles via handling in the glove box). The experimental procedure for the third test was modified to address both of these concerns, as described in the previous section. 
Table 2. Gallium extraction in first test (extraction/scrub)

\begin{tabular}{|c|c|c|c|c|c|}
\hline Phase & $\begin{array}{c}\text { Volume } \\
\text { (mL) }\end{array}$ & $\begin{array}{c}\mathrm{HNO}_{3} \\
(M)\end{array}$ & $\begin{array}{c}\mathrm{Ga} \\
(\mathrm{Bq} / \mathrm{mL})\end{array}$ & $\mathrm{K}_{\mathrm{d}}$ & $\mathrm{DF}^{a}$ \\
\hline \multicolumn{6}{|l|}{ Extraction } \\
\hline Aqueous feed & 5.0 & 4.0 & $1.29 \mathrm{H} 10^{5}$ & \multirow{4}{*}{$<1.8 \mathrm{H}_{10}^{-5}$} & \multirow{4}{*}{$>5.5 \mathrm{H}_{10} 0^{4}$} \\
\hline Organic feed & 6.00 & $b$ & 0 & & \\
\hline Organic extract & $6.26^{c}$ & $0.6^{c}$ & $<2.35$ & & \\
\hline Aqueous raffinate & $4.8^{c}$ & $3.2^{c}$ & $b$ & & \\
\hline \multicolumn{6}{|l|}{ Scrub } \\
\hline Organic feed & $6.2^{c, d}$ & $0.6^{c}$ & $<2.35$ & \multirow{4}{*}{$<9.1 \mathrm{H} 10^{-6}$} & \multirow{4}{*}{$>1.1 \mathrm{H} 10^{5}$} \\
\hline Aqueous scrub & 2.5 & 4.0 & 0 & & \\
\hline Scrubbed organic & $6.1^{c}$ & $0.6^{c}$ & $<1.17$ & & \\
\hline Aqueous raffinate & $2.6^{c}$ & $4.0^{c}$ & $b$ & & \\
\hline
\end{tabular}

${ }^{a}$ Gallium DF normalized per unit of plutonium in feed.

${ }^{b}$ Not measured.

${ }^{c}$ Values based on SEPHIS calculation from input streams. Source: A. D. Mitchell, SEPHISMOD 4: A User's Manual to a Revised Model of the Purex Solvent Extraction System, ORNL-5471 (May 1979).

${ }^{d}$ An estimated $0.1 \mathrm{~mL}$ of organic was lost to samples after the extraction step.

Table 3. Gallium extraction in second test (extraction/scrub/strip)

\begin{tabular}{|c|c|c|c|c|c|}
\hline Phase & $\begin{array}{l}\text { Volume } \\
(\mathrm{mL})\end{array}$ & $\begin{array}{c}\mathrm{HNO}_{3} \\
(M)\end{array}$ & $\begin{array}{c}\mathrm{Ga} \\
(\mathrm{Bq} / \mathrm{mL})\end{array}$ & $\mathrm{K}_{\mathrm{d}}$ & $\mathrm{DF}^{a}$ \\
\hline \multicolumn{6}{|l|}{ Extraction } \\
\hline Aqueous feed & 5.0 & 4.5 & $6.06 \mathrm{H} 10^{5}$ & \multirow{4}{*}{$<2.7 \mathrm{H} 10 \mathrm{G}^{6}$} & \\
\hline Organic feed & 5.0 & $0.03^{b}$ & 0 & & \\
\hline Organic extract & $5.2^{b}$ & $0.6^{b}$ & $<1.73$ & & $>3.4 \mathrm{H} 10^{5}$ \\
\hline Aqueous raffinate & $4.8^{b}$ & $4.0^{b}$ & $c$ & & \\
\hline \multicolumn{6}{|l|}{ Scrub } \\
\hline Organic feed & $5.2^{b, d}$ & $0.6^{b}$ & $<1.73$ & & \multirow{4}{*}{$1.4 \mathrm{H} 10^{5}$} \\
\hline Aqueous scrub & 1.63 & 1.5 & 0 & & \\
\hline Scrubbed organic & $5.1^{b}$ & $0.4^{b}$ & $4.3( \pm 45 \%)$ & & \\
\hline Aqueous raffinate & $1.7^{b}$ & $2.2^{b}$ & $c$ & & \\
\hline \multicolumn{6}{|l|}{ Plutonium strip } \\
\hline Organic feed & $5.0^{b, d}$ & $0.4^{b}$ & $4.3( \pm 45 \%)$ & \multirow{4}{*}{7.5} & \\
\hline Aqueous strip & 5.00 & $e$ & 0 & & \\
\hline Stripped organic & $4.8^{b}$ & $0.13^{b}$ & $52( \pm 2 \%)$ & & \\
\hline $\begin{array}{l}\text { Aqueous plutonium } \\
\text { product }\end{array}$ & $5.1^{b}$ & $0.6^{b}$ & $6.9(+12 \%)$ & & $9 \mathrm{H} 10^{4}$ \\
\hline $\begin{array}{l}{ }^{6} \text { Gallium DF normalize } \\
\text { Values based on SEPI } \\
\text { Not measured. } \\
{ }^{d} \text { An estimated } 0.1 \mathrm{~mL} \\
\text { test. } \\
0.1 \mathrm{MNO}_{3}-0.4 \mathrm{M}\end{array}$ & $\begin{array}{l}\text { unit pluton } \\
\text { alculation }\end{array}$ & $\begin{array}{l}\text { in feed. } \\
n \text { input str }\end{array}$ & the extract & step and af & the scrub \\
\hline
\end{tabular}




\subsubsection{Results of Test 3}

In the third test, the operational problems observed in the second experiment were eliminated, as no evidence of sample contamination was apparent. Gallium extraction results are provided in Table 4. The feed activity was about 25 -fold larger, thereby increasing the sensitivity of the test. The DFs were significantly in excess of the target value of $10^{6}$ in all plutonium product fractions. The first-stage organic extract showed a DF of $3.6 \mathrm{H} 10^{6}( \pm 25 \%)$, with a detectable gallium gamma peak that provided a real value (although the error bar is rather large). The $\mathrm{K}_{\mathrm{d}}$ for gallium in this chemical system is approximately $3 \mathrm{H}^{-7}$. Both the scrubbed organic and the stripped aqueous plutonium product were below the limit of

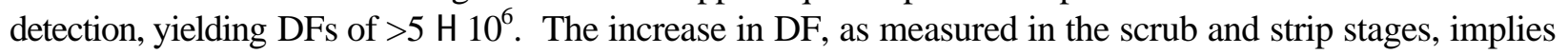
that even larger DFs are possible, as far as fundamental chemical considerations are concerned.

Therefore, the limiting factor in practice will depend on engineering design and operational aspects of the facility.

Table 4. Gallium extraction in third test (extraction/scrub/strip)

\begin{tabular}{|c|c|c|c|c|c|}
\hline Phase & $\begin{array}{l}\text { Volume } \\
\text { (mL) }\end{array}$ & $\begin{array}{c}\mathrm{HNO}_{3} \\
(M) \\
\end{array}$ & $\begin{array}{c}\mathrm{Ga} \\
(\mathrm{Bq} / \mathrm{mL})\end{array}$ & $\mathrm{K}_{\mathrm{d}}$ & $\mathrm{DF}^{a}$ \\
\hline \multicolumn{6}{|l|}{ Extraction } \\
\hline Aqueous feed & 5.00 & 4.5 & $1.50 \mathrm{H} 10^{7}( \pm 1.7 \%)$ & \multirow{4}{*}{$2.8 \mathrm{H} 10^{-7}$} & \multirow{4}{*}{$3.6 \mathrm{H} 10^{6}$} \\
\hline Organic feed & 5.00 & $0.03^{b}$ & 0 & & \\
\hline Organic extract & $5.2^{b}$ & $0.6^{b}$ & $4.0( \pm 26 \%)$ & & \\
\hline Aqueous raffinate & $4.8^{b}$ & $2.9^{b}$ & $c$ & & \\
\hline \multicolumn{6}{|l|}{ Scrub } \\
\hline Organic feed & $5.0^{b, d}$ & $0.6^{b}$ & $4.0( \pm 26 \%)$ & \multirow{4}{*}{$<0.51$} & \multirow{4}{*}{$>6.4 \mathrm{H}_{10} 0^{6}$} \\
\hline Aqueous scrub & 1.63 & 1.5 & 0 & & \\
\hline Scrubbed organic & $5.0^{b}$ & $0.4^{b}$ & $<2.3$ & & \\
\hline Aqueous raffinate & $1.7^{b}$ & $2.2^{b}$ & 8.8 & & \\
\hline \multicolumn{6}{|l|}{ Plutonium strip } \\
\hline Organic feed & $4.8^{b, d}$ & $0.4^{b}$ & $<2.3$ & & \multirow[b]{4}{*}{$>5 \mathrm{H}^{1} 0^{6}$} \\
\hline Aqueous strip & 10.0 & $e$ & 0 & & \\
\hline Stripped organic & $4.65^{b}$ & $0.08^{b}$ & $<0.4$ & & \\
\hline $\begin{array}{l}\text { Aqueous plutonium } \\
\text { product }\end{array}$ & $10.1^{b}$ & $0.4^{b}$ & $<1.3$ & & \\
\hline $\begin{array}{l}{ }^{a} \text { Gallium DF compare } \\
{ }^{b} \text { Values based on SEI } \\
{ }^{c} \text { Not measured. } \\
{ }^{d} \text { An estimated } 0.2 \mathrm{~mL} \\
\text { step. } \\
{ }^{e} 0.1 \mathrm{MHNO}-0.4 \mathrm{M}\end{array}$ & $\begin{array}{l}\text { feed, norma } \\
\text { calculatior } \\
\text { organic was }\end{array}$ & $\begin{array}{l}\text { ed per uni } \\
\text { som input }\end{array}$ & $\begin{array}{l}\text { olutonium. } \\
\text { reams. } \\
\text { es after the extraction }\end{array}$ & step and aft & the scrub \\
\hline
\end{tabular}

\subsection{PLUTONIUM EXTRACTION}

Plutonium behaved essentially as expected on the basis of SEPHIS code modeling. Batch tests such as these do not replicate continuous countercurrent performance in several respects. Most significantly, the 
various raffinate streams remove some of the plutonium in batch tests, such that every effluent stream carries a significant amount of plutonium. In contrast, this plutonium is recovered internally within the system in countercurrent operation, so essentially all the plutonium exits the system in a single product stream.

Plutonium behavior is illustrated by the results for the third test, which are reported in Table 5. Relative plutonium contents are measured by the integrated count in the $5.15-\mathrm{MeV}$ alpha-energy peak, which is characteristic of the activity of the two isotopes ${ }^{239} \mathrm{Pu}$ and ${ }^{240} \mathrm{Pu}$. The last column of the table gives the results from a SEPHIS code calculation for the same conditions. Within experimental error, reasonably good agreement exists. As expected, the plutonium behavior was normal.

Table 5. Plutonium extraction in third test (extraction/scrub/strip)

\begin{tabular}{|c|c|c|c|c|c|}
\hline \multirow{2}{*}{ Phase } & \multirow{2}{*}{$\begin{array}{l}\text { Volume } \\
(\mathrm{mL})\end{array}$} & \multirow{2}{*}{$\begin{array}{l}\mathrm{HNO}_{3} \\
(M)\end{array}$} & \multirow{2}{*}{$\begin{array}{c}\text { 5.15-MeV peak } \\
(\mathrm{Bq} / \mathrm{mL})\end{array}$} & \multicolumn{2}{|c|}{ Percentage of plutonium } \\
\hline & & & & Experimental & SEPHIS \\
\hline \multicolumn{6}{|l|}{ Extraction } \\
\hline Aqueous feed & 5.00 & 4.5 & $1.04 \mathrm{H}_{10}^{8}$ & 100 & 100 \\
\hline Organic feed & 5.00 & $0.03^{a}$ & 0 & & \\
\hline Organic extract & $5.2^{a}$ & $0.6^{a}$ & $9.3 \mathrm{H}_{10} 0^{7}$ & 92 & 93.3 \\
\hline Aqueous raffinate & $4.8^{a}$ & $2.9^{a}$ & $1.1 \mathrm{H}^{1} 0^{7}$ & 10 & 6.7 \\
\hline \multicolumn{6}{|l|}{ Scrub } \\
\hline Organic feed & $5.0^{a, b}$ & $0.6^{a}$ & $9.3 \mathrm{H}_{10}{ }^{7}$ & 100 & 100 \\
\hline Aqueous scrub & 1.63 & 1.5 & 0 & & \\
\hline Scrubbed organic & $5.0^{a}$ & $0.4^{a}$ & $8.0 \mathrm{H}^{7} 0^{7}$ & 86 & 93.8 \\
\hline Aqueous raffinate & $1.7^{a}$ & $2.2^{a}$ & $2.1 \mathrm{H} 10^{7}$ & 8 & 6.2 \\
\hline \multicolumn{6}{|l|}{ Plutonium strip } \\
\hline Organic feed & 4.8 & 0.4 & $8.0 \mathrm{H}^{1} 0^{7}$ & 100 & 100 \\
\hline Aqueous strip & 10.0 & $c$ & 0 & & \\
\hline Stripped organic & $4.65^{a}$ & $0.08^{a}$ & $1.75 \mathrm{H} 10^{6}$ & 2 & 1 \\
\hline $\begin{array}{l}\text { Aqueous plutonium } \\
\text { product }\end{array}$ & $10.1^{a}$ & $0.4^{a}$ & $3.35 \mathrm{H} 10^{7}$ & 90 & 99 \\
\hline
\end{tabular}

${ }^{a}$ Values based on SEPHIS calculation from input streams.

${ }^{b}$ An estimated $0.2 \mathrm{~mL}$ of organic was lost to samples after the extraction step and after the scrub step.

${ }^{c} 0.1 M \mathrm{HNO}_{3}-0.4 M \mathrm{HAN}$.

\section{CONCLUSIONS}

Experiments have been carried out to determine whether or not removal of gallium from WG-Pu would present any unexpected or unusual problems in the PUREX process, since it may be necessary to reduce the gallium content of the plutonium to a very low level. Based on successful $\mathrm{UO}_{2}$ fuel history, a conservative estimate is made that a gallium impurity level of $10 \mathrm{ppb}$, relative to plutonium, is acceptable. (This corresponds to a gallium DF of $10^{6}$, based on $1 \%$ initial gallium in the WG-Pu.) At this level, gallium generated by neutron capture in natural zinc impurity may dominate, so the zinc specifications of materials used to fabricate the $\mathrm{MOX}$ fuel $\left(\mathrm{PuO}_{2}\right.$ and $\mathrm{UO}_{2}$ oxides and cladding alloy) are key factors.

The experimental procedure approximated the proposed flowsheet for WG-Pu purification, except that only one stage was used for each process: extraction, scrubbing, and stripping. With realistic multistage 
countercurrent systems, much more efficient separations are generally obtained. The measured gallium

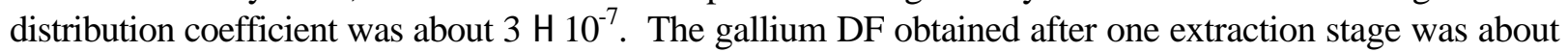
$3 \mathrm{H}_{10}{ }^{6}$. After one scrub stage, all gallium measurements were less than the detection limit, which corresponded to DFs $>5 \mathrm{H} 10^{6}$. All these values exceed the $10^{6} \mathrm{DF}$ needed to meet the 10 -ppb gallium specification.

The results of this study showed no inherent or fundamental problem with regard to removing gallium from plutonium. Therefore, the purification obtained in practice will be limited primarily by operational procedures and equipment design. Close attention to operational detail and good system design should enable a conservative 10-ppb gallium limit to be met.

Information obtained from literature references indicates that the presence of other impurities, such as chloride, may degrade the achievable decontamination of plutonium from gallium. Thus, the effects of various concentrations of chloride and other potential impurities on the achievable DF from gallium many need to be established in experiments similar to those conducted in this study. Additional studies to determine the effects of chloride and other impurities on gallium DFs would be useful.

\section{ACKNOWLEDGMENTS}

The authors wish to acknowledge the assistance of C. W. Alexander and D. C. Glasgow with the irradiations to produce the ${ }^{72} \mathrm{Ga}$ tracer for use in these tests, C. D. Parks and the Transuranium Analysis Group with the alpha and gamma analyses, and C. E. Porter and R. D. Vandergrift with the glove box operations and sampling. The authors also acknowledge Vanessa B. Brown for help in preparing the manuscript. Funding for this project was provided by the DOE Office of Fissile Materials Disposition. 


\section{REFERENCES}

1. R. P. Wichner and R. N. Morris, Gallium Strategy, ORNL/TM-13667, July 1998.

2. D. F. Wilson et al., Interactions of Zircaloy Cladding with Gallium: Final Report, ORNL/TM-13684, September 1998.

3. M. K. West, Gallium Interactions with Zircaloy, Texas A\&M University, ANRCP-1999-2, January 1999.

4. B. Cox and Y. M. Wong, "Liquid Metal Embrittlement of Zr-2.5\% Nb Alloy," J. Nucl. Mater. 245, 34-43 (1997).

5. Personal communication with Jean-Paul Moulin, SGN, at Oak Ridge National Laboratory meeting with Framatome COGEMA Fuels, Oak Ridge, Tennessee, June 17, 1999.

6. A. G. Croff and C. W. Alexander, Decay Characteristics of Once-Through LWR and LMFBR Spent Fuels, High-Level Wastes, and Fuel-Assembly Structural Material Wastes, ORNL/TM-7431, November 1980.

7. D. O. Campbell, Product Decontamination in Purex Processing, ORNL/CFRP-89/9, 1989.

8. D. E. Benker, J. E. Bigelow, W. D. Bond, F. R. Chattin, L. J. King, F. G. Kitts, R. G. Ross, and R. G. Stacy, Solvent Extraction Studies with High-Burnup Fast Flux Test Facility Fuel in the Solvent Extraction Test Facility, ORNL/TM-9993, 1986.

9. D. A. Orth, R. M. Wallace, and D. G. Karraker, "Solvent Extraction Reactions and Mechanisms," p. 173 in The Science and Technology of Tributyl Phosphate, Vol. 1, ed. W. W. Schulz and J. D. Navratil, CRC Press, Boca Raton, Florida, 1984.

10. T. Ishimori and K. Watanabe, Bull. Chem. Soc. Jpn. 33, 1443 (1960)

11. T. Ishimori and K. Watanabe, Bull. Chem. Soc. Jpn. 33, 636 (1960).

12. K. A. Kraus and F. Nelson, p. 83 in Proceedings of the International Conference on the Peaceful Uses of Atomic Energy, Geneva, 1955, Vol. VII, United Nations, Geneva, 1956. 


\section{INTERNAL DISTRIBUTION}

$\begin{aligned} \text { 1. } & \text { C. W. Alexander } \\ \text { 2. } & \text { D. E. Benker } \\ 3 . & \text { B. B. Bevard } \\ 4 . & \text { D. O. Campbell } \\ 5-10 . & \text { E. D. Collins } \\ \text { 11. } & \text { B. S. Cowell } \\ \text { 12. } & \text { L. K. Felker } \\ \text { 13. } & \text { S. R. Greene } \\ \text { 14. } & \text { S. A. Hodge } \\ \text { 15. } & \text { R. T. Jubin } \\ \text { 16. } & \text { J. B. Knauer } \\ \text { 17. } & \text { L. E. McNeese } \\ \text { 18. } & \text { G. E. Michaels }\end{aligned}$

19. R. N. Morris

20. D. G. O’Connor

21. C. D. Parks

22. B. D. Patton

23. C. E. Porter

24. R. T. Primm III

25. D. J. Spellman

26. L. M. Toth

27. R. M. Wham

28. D. F. Williams

29. K. A. Williams

30. Lab Records, RC

31. Lab Records, OSTI

\section{EXTERNAL DISTRIBUTION}

32. D. Alberstein, Los Alamos National Laboratory, 528 35th Street, Los Alamos, NM 87544

33. J. F. Baker, U.S. Department of Energy, MD-30, 1000 Independence Avenue, SW, Forrestal Building, 6G-050, Washington, DC 20585

34. M. G. Bale, Framatome Cogema Fuels, 3315 Old Forest Road, P.O. Box 10935, Lynchburg, VA 24506-0935

35. M. P. Broussard, Duke, Cogema, Stone and Webster, 400 South Tryon Street, Charlotte, NC 28202

36. A. Caponiti, U.S. Department of Energy, MD-30, 1000 Independence Avenue, SW, Forrestal Building, 6G-050, Washington, DC 20585

37. S. DeMuth, Los Alamos National Laboratory, 528 35th Street, Los Alamos, NM 87544

38. L. Giaffe, Duke, Cogema, Stone and Webster, 400 South Tryon Street, Charlotte, NC 28202

39. J. V. Johnson, U.S. Department of Energy, MD-12, 1000 Independence Avenue, SW, Forrestal Building, 6G-050, Washington, DC 20585

40. L. Losh, Framatome Cogema Fuels, 3315 Old Forest Road, P.O. Box 10935, Lynchburg, VA 24506-0935

41. G. Meyer, Framatome Cogema Fuels, 3315 Old Forest Road, P.O. Box 10935, Lynchburg, VA 24506-0935

42. J. P. Moulin, SGN, 1 Rue des Herons Montigny le Bretonnaux 78182 St. Quentin Yvelines, Cedex France

43. D. Nulton, U.S. Department of Energy, MD-10, 1000 Independence Avenue, SW, Forrestal Building, 6G-050, Washington, DC 20585

44. P. T. Rhoads, U.S. Department of Energy, MD-12, 1000 Independence Avenue, SW, Forrestal Building, 6G-050, Washington, DC 20585

45. J. H. Thompson, Department of Energy, MD-12, 1000 Independence Avenue, SW, Forrestal Building, 6G-050, Washington, DC 20585

46. S. Zygmunt, Los Alamos National Laboratory, 528 35th Street, Los Alamos, NM 87544 